\title{
EFEITOS LOCAIS E DE LARGA ESCALA NA DINÂMICA CLIMÁTICA DO MUNICÍPIO DE
} VIÇOSA - MINAS GERAIS

\section{Local and large scale effects on climate dynamics in Viçosa - Minas Gerais}

\author{
Jackson Martins Rodrigues \\ Mestrando em Meteorologia Agrícola pela Universidade Federal de Viçosa \\ Viçosa/MG - Brasil \\ jacksonmrodrigues@gmail.com \\ Rafael de Ávila Rodrigues \\ Doutorando em Meteorologia Agrícola pela Universidade Federal de Viçosa
}

Viçosa/MG - Brasil

rafaelvo@hotmail.com

Flávio Barbosa Justino

Professor do Departamento de Engenharia Agrícola da Universidade Federal de Viçosa

Viçosa/MG - Brasil

fjustino@ufv.br

Luiz Cláudio Costa

Professor do Departamento de Engenharia Agrícola da Universidade Federal de Viçosa

Viçosa/MG - Brasil

1.costa@ufv.br

Marcelo Cid de Amorim

Professor da Universidade Federal Rural do Rio de Janeiro

Três Rios/RJ - Brasil

cid_amorim@hotmail.com

Artigo recebido para publicação em 11/03/2010 e aceito para publicação em 09/11/2010

RESUMO: O município de Viçosa - MG, que desde sua fundação tem apresentado vertiginoso crescimento da sua área urbana devido, principalmente, a implantação e ampliação da Universidade Federal de Viçosa. Neste sentido, o objetivo deste trabalho foi levantar registros que demonstrem que o crescimento urbano de Viçosa vem causando impactos no comportamento climático local. Para tanto foram coletadas informações sobre a cidade junto a órgãos públicos e dados climáticos junto à estação meteorológica do INMET instalada na UFV. E, por meio da normalização das variáveis climáticas e do teste Mann-Kendall observou-se que as temperaturas mínimas estão apresentando tendências, enquanto que temperaturas máximas, não apresentaram grandes alterações em seus padrões. Observou-se que as temperaturas médias de Viçosa, Região Sudeste do Brasil e Minas Gerais apresentam forte correlação e por meio do teste " $t$ " de student mostrou estatisticamente significativo a niveis de significância de 10\%, 5\% e 1\%, e que os desvios positivos das temperaturas mínimas são influenciados pelas pressões de vapor e de saturação. Desta forma, em termos de em grande escala, concluiu-se que os padrões climáticos em Viçosa (MG) estão relacionados, dinamicamente, pela a interação de sistemas de circulação atmosféricas reinantes e a fisiografia da região. Todavia, o processo de expansão e 
urbanização que vem ocorrendo não apresenta potencial suficiente de alterar tais padrões climáticos. Contudo, observaram-se impactos em algumas variáveis meteorológicas, em especial, na temperatura mínima e até no conteúdo de água na atmosfera. O impacto está relacionado com o transporte e armazenamento de calor oriundo do aumento da área urbana e volume de água fornecido à população que são, naturalmente, assimilados pelos sensores da estação meteorológica.

Palavras-chave: Clima Urbano. Urbanização. Circulação Atmosférica. Viçosa

\begin{abstract}
The cities come passing for a continuous process of changes since the Industrial Revolution with accented growth, substituting the vegetal coverings for waterproof materials influencing the climatic standards. The city of Viçosa - MG is had as example, that since its foundation has presented vertiginous growth of its urban area mainly from the installation of the Federal University of Viçosa. In such a way this work had as objective to raise given that they demonstrated the urban growth of Viçosa and to identify by means of comparisons and adjusted statistical tests if it has influences in the local climatic behavior. For climatic information on the city next to public agencies and data next to meteorological station of the INMET installed in the UFV had been in such a way collected. By means of the normalization of the climatic 0 variable and the Mann-Kendall test it was observed that the minimum temperatures are presenting trends, whereas maximum temperatures, had not presented great alterations in its standards. It was observed that the average temperatures of Viçosa, Southeastern Region of Brazil and Minas Gerais present fort correlation and by means of test $t$ student statistical showed significant the levels of significance of $10 \%, 5 \%$ and $1 \%$, and that the positive shunting lines of the minimum temperatures are influenced by the saturation and vapor pressures. In such a way one concluded that the climatic standards presented by Viçosa are related the systems of regional atmospheric circulation and with the fisiography of the city, being that the occured urbanization in the city does not present great capacity to modify the climatic standards.
\end{abstract}

Keywords: Urban climate. Urbanization. Atmospheric circulation. Viçosa. Minas Gerais.

\section{INTRODUÇ̃̃O}

Segundo Spirn (1995), a qualidade da atmosfera urbana preocupa a humanidade desde o império romano devido aos aromas liberados pelas cozinhas. Contudo, o primeiro estudo que se tem notícia, sobre o clima urbano, ocorreu em Londres, em 1661, estudo motivado por observações que a queima de carvão estava produzindo alterações na temperatura da cidade. Em 1787, na cidade alemã de Munique, ocorreram discursos acirrados devido o odor da cidade e suas condições atmosféricas, e que principalmente após a Revolução Industrial, muitas alterações no clima da cidade foram constatadas tendo como agravante o efeito do crescimento populacional e o desordenamento urbano.

Segundo Saydelles (2005), em 1883, o químico Howard concluiu que o ar da cidade de Londres estava contaminado e as temperaturas estavam mais altas na cidade que em seus arredores, fenômeno atualmente definido como ilha de calor. Entretanto, a atmosferas nos centros urbanos só foram estudadas detalhadamente no século XX, devido a esforços de geógrafos e meteorologistas que se interessaram em estudar os impactos do processo de urbanização e industrialização, principalmente, após a $2^{\mathrm{a}}$ Guerra Mundial.

Monteiro (1976) notou que embora tenha ocorrido uma grande evolução nos métodos de análise e na epistemologia da ciência, até meados do século $\mathrm{XX}$, os estudos sobre clima urbano apenas investigavam sob aspectos meteorológicos dando pouco destaque a degradação ambiental proveniente de atividade antrópica. Todavia, a partir destas observações geógrafos, climatólogos e estudiosos do ambiente 
urbano vêm produzindo críticas aos trabalhos que não enfatizam a necessidade de estudar os demais elementos presentes no clima urbano.

Contudo, podemos citar outros estudos, como os propostos Oke (1978) que inseriu o conceito denominado de "Sky View Factor (SKF), utilizado primeiramente pela Biologia para estudos de radiação em florestas e por Olgyay, em 1973, para ambientes arquitetônicos. O SKF é utilizado para quantificar a abertura para o céu em determinados pontos da superfície para que sejam realizadas as trocas de energia com a superfície.

Quereda Sala (2000) em seu estudo sobre o impacto da expansão urbana na Espanha, na porção Mediterrânea, encontrou aumento de $0,57^{\circ} \mathrm{C}$ na temperatura média a partir a segunda metade século XX e este foi associado à expansão urbana envolvendo as estações meteorológicas presentes no local. Sendo ainda, enfatizado que comparando a evolução das temperaturas urbanas e rurais as tendências das primeiras se mostraram com desvios positivos maiores.

De acordo com Araújo e Sant'Anna Neto (2002), na cidade de São Luís (MA) o aquecimento diurno ocorre com maior freqüência em áreas mais urbanizadas com maiores concentrações de pessoas, construções e automóveis.

Amorim (2002) argumenta que a cidade de Presidente Prudente (SP) vem apresentando alterações relevantes no clima decorrente do crescimento urbano desordenado, tendo como conseqüência diferenças de temperatura e umidade entre suas áreas intra-urbana e rural, afirmando assim que há formação de clima urbano originado da combinação do tipo de uso e ocupação do solo com carência de cobertura vegetal.

Na cidade de Viçosa (MG), alguns trabalhos no ambiente urbano demonstram a ocorrência de impactos no clima da cidade sendo associada à expansão urbana. Segundo Dutra, Coutinho e Fialho (2006), não observou alterações pluviométricas no município, contudo as constantes inundações são resultados do desordenamento urbano. Por sua vez, Santos (2007) associou o fenômeno de ilhas de calor, ou seja, um aumento das temperaturas noturnas em Viçosa, ao processo intenso está relacionada intensa urbanização e atividades econômicas desenvolvidas durante a semana, concluindo que há mobilidade espacial dos núcleos de calor nos fins de semana.
Alcântara (2008), em seu trabalho que tratou qualitativamente as sensações térmicas da população de Viçosa MG, concluiu que tanto na zona urbana quanto na rural as pessoas têm seu bem estar e suas decisões influenciadas pelas condições do tempo e do clima.

Questões climáticas, seja em cidades ou regiões, ficam mais notórias quando alteramos o ambiente sem um prévio estudo de planejamento ou análises de possíveis impactos. O município de Viçosa - MG e a própria Universidade Federal Viçosa (UFV) vêm experimentando, ao longo desses últimos anos, um crescimento vertiginoso na área edificada e pavimentada - até mesmo em torno da estação meteorológica - o que certamente vem causando mudanças na paisagem e possivelmente no clima local.

Neste sentido, o setor de meteorologia da UFV vem sugerindo alterações no padrão climático, principalmente, na temperatura mínima, contudo, pouco se tem estudado a respeito da influência que a urbanização tem causado no clima local ou sua influencia em outras variáveis meteorológicas de rotina.

Deste modo, este estudo buscou identificar alterações e tendências do clima de Viçosa (MG), fornecendo subsídios para elaboração de trabalhos científicos com abordagens mais consistentes e confiáveis a respeito do assunto. Foram considerados a intensa urbanização do município e o processo de infraestruturação da UFV. No estudo, localmente, serão considerados aspectos socioeconômicos e urbanísticos. E, regionalmente, os principais fenômenos da dinâmica atmosférica, em mesoescala, predominantes em Minas Gerais e no Sudeste Brasileiro.

\section{METODOLOGIA}

\section{Registros Meteorológicos}

Para caracterização do clima local, foi realizado um levantamento de registro meteorológicos na estação do Instituto Nacional de Meteorologia - INMET no 83642, instalada no campus da Universidade Federal de Viçosa - UFV entre o período de 1968 a 2008. Essa coletânea de registros representa uma série contínua e ininterrupta de dados meteorológicos. 
Considerando uma grade global, e em termos de resolução escalar, foram obtidos registros de temperatura média (máxima e mínima), em séries, por meio de campo de reanálise do "National Centers for Environmental Prediction = NCEP" numa célula de grade correspondente a região de Viçosa (MG). As séries meteorológicas foram construídas entre 1968 a 2008.

Para representar o processo de expansão e crescimento populacional em Viçosa foi sistematizado, para os últimos 33 anos, o consumo de água pela população, em $\mathrm{m}^{3}$. Este volume monitorado continuamente pelo Serviço Autônomo de Águas e Esgoto (SAAE). Todavia, outras fontes de dados também foram utilizadas para expressar o crescimento urbano em Viçosa, por exemplo: registros populacionais junto ao Instituto Brasileiro de Geografia e Estatística (IBGE, 2000; IBGE, 2007) a partir do censo demográfico de 1950; evolução da frota; Impostos sobre circulação de mercadorias e prestação de serviços (ICMS) e outras taxas que demonstram o ritmo de crescimento econômico da cidade no período de 1980 a 2007.

E por fim, em termos de impactos da urbanização, serão utilizados fotos panorâmicas a fim de demonstrar a evolução das construções, ao longo dos anos, e para tanto, buscou-se arquivos históricos fotográficos da UFV e em publicações que retratam a história da cidade.

\section{Tratamento Estatístico}

O tratamento dos dados meteorológicos coletados na estação local foi feito por meio de técnicas estatísticas específicas às séries meteorológicas. Ou seja, primeiramente, foi feito o teste não paramétrico de Mann-Kendall, que identifica a existência tendências em séries meteorológicas e hidrológicas. Permitindo ainda a detecção e localização do ponto inicial da alteração em determinada tendência. Este teste vem sendo recomendado pela Organização Meteorológica Mundial (OMM) para estudos de tendências em séries temporais de elementos meteorológicos (YU et al., 2002). Silveira e Gan (2006) notam que o teste de Mann-Kendall pode ser usado em séries descontínuas com distribuição desconhecida, com a vantagem de usar a magnitude relativa dos valores da série. Assumindo a hipótese nula $\left(\mathrm{H}_{\mathrm{o}}\right)$, ausência de tendência, os dados precisam ser variáveis aleatórias, independentes e identicamente distribuída. A equação (1) representa a teste de Man-Kendall

$$
S=\sum_{j=i+1}^{n}\left(R_{j}-R_{i}\right)
$$

Em que, $R_{j}$ e $R_{i}$ representam a ordem relativa de cada elemento da série temporal. As diferenças $\left(\mathrm{R}_{\mathrm{j}}-\mathrm{R}_{\mathrm{i}}\right)$ recebem valor zero $(0) \mathrm{se}\left(\mathrm{R}_{\mathrm{j}}-\mathrm{R}_{\mathrm{i}}\right)=0$; [-1] se $\left(R_{j}-R_{i}\right)>0$ e, por fim, [1] se $\left(R_{j}-R_{i}\right)<0$. Supondo $H_{0}$ seja verdadeira, o $\mathrm{S}$ deve apresentar uma distribuição aproximadamente normal com média zero e variância $\operatorname{Var}(\mathrm{S})=[(\mathrm{n} *(\mathrm{n}-1) *(2 * \mathrm{n}+5)] / 18$. Finalmente a estatística de teste $\mathrm{Z}$ é dada por:

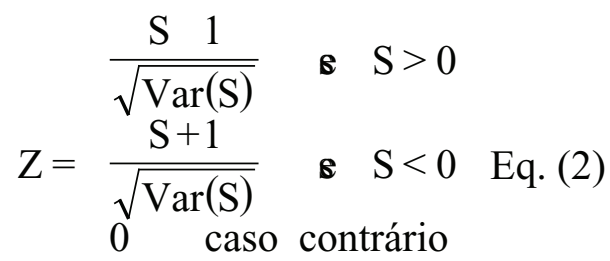

Adotando um nível de significância de 95\%, $\mathrm{H}_{0}$ é rejeitado se $|\mathrm{Z}|>\mathrm{z}_{\alpha / 2}$, em que o valor $\mathrm{z}_{\alpha / 2}=1,96$ é obtido da tabela normal padrão. $O$ sinal da estatística $Z$ indicará se a tendência é positiva $(Z>0)$ ou negativa $(\mathrm{Z}<0)$.

Os dados coletados na estação foram normalizados com aplicação da equação (3) que retira a tendência dos dados da série histórica e desta maneira demonstra o real comportamento das séries meteorológicas. Tal equação consiste na subtração da média de um determinado mês de um ano, pela média do mesmo mês em todos os anos dividindo pelo desvio padrão.

$$
\mathrm{y}=\frac{\mathrm{xi} \overline{\mathrm{x}}}{\text { ó }}
$$


Em que, $=\sigma$ desvio padrão, $=\bar{x}$ média do mesmo mês em todos os anos, $\mathrm{x}_{\mathrm{i}}=$ média de cada mês.

Após coletados os dados das séries de temperaturas médias, regionalizado, para Região Sudeste do Brasil e do Estado de Minas Gerais foi realizada uma análise de correlação entre as mesmas e os dados históricos das temperaturas médias coletadas na estação do INMET de Viçosa - MG.

A significância dos coeficientes de correlação gerados pela regressão linear entre as variáveis $X_{i}, X_{j}$, para $\mathrm{i} \neq \mathrm{j}$, têm distribuição normal univariada e foi testada por meio do teste de hipótese de "t student" como sugerido por Mingoti (2007). Assim se $\mathrm{p}_{\mathrm{ij}}$ representa a correlação teórica entre $\mathrm{x}_{\mathrm{i}}$ e $\mathrm{X}_{\mathrm{j}}$, as hipóteses: $\mathrm{h}_{0}: \mathrm{p}_{\mathrm{ij}}$ $=0$ contra $\mathrm{H}_{1}: \mathrm{p}_{\mathrm{ij}} \neq 0$ podem ser testadas por meio da equação 4.

$$
\mathrm{t}=\mathrm{R}_{\mathrm{ij}} \frac{\sqrt{\mathrm{n} 2}}{\sqrt{1 \mathrm{R} 2}} \text { Eq. (4) }
$$

Em que n representa o número de observações. Onde $\mathrm{R}_{\mathrm{ij}}$ é a correlação amostral observada entre $\mathrm{X}_{\mathrm{i}}$ e $X_{j}$. Sob a hipótese nula, a estatística aplicada pela equação (4) tem uma distribuição em $t$ student com (n - 2). Assim, para um nível de significância $\alpha, 0<\alpha<1$, encontra-se na tabela $t$ de student o correspondente valor critico $t^{c}$ tal que:

$$
\text { PROB }\left[\text { Tn }-2>t^{c}\right]=\alpha / 2 \quad \text { Eq. (5) }
$$

Ou seja, se o valor observado pela estatística do teste t, equação 4 , tiver valor absoluto e exceder ao valor critico $t^{\mathrm{C}}$, a hipótese nula deve ser rejeitada. Desse modo, supondo-se que a distribuição normal seja válida para as variáveis, fez-se o teste $t$ de student para verificar se as correlações entre as variáveis são significativas ou não em nível de 10\%, 5\% e 1\%.

\section{RESULTADOS E DISCUSSÕES}

\section{Caracterização Climática de Viçosa - MG. Séries:} 1961-1990 e 1968 - 2008

Em seus aspectos climáticos, Viçosa apresenta períodos bem definidos com invernos secos e frios e verões quentes e úmidos. Esta variação ocorre devido à atuação dos sistemas atmosféricos, ocasionando a sucessão de vários tipos de tempo.

Como demonstrado na Figura 1, os maiores registros médios de temperatura estão entre os meses

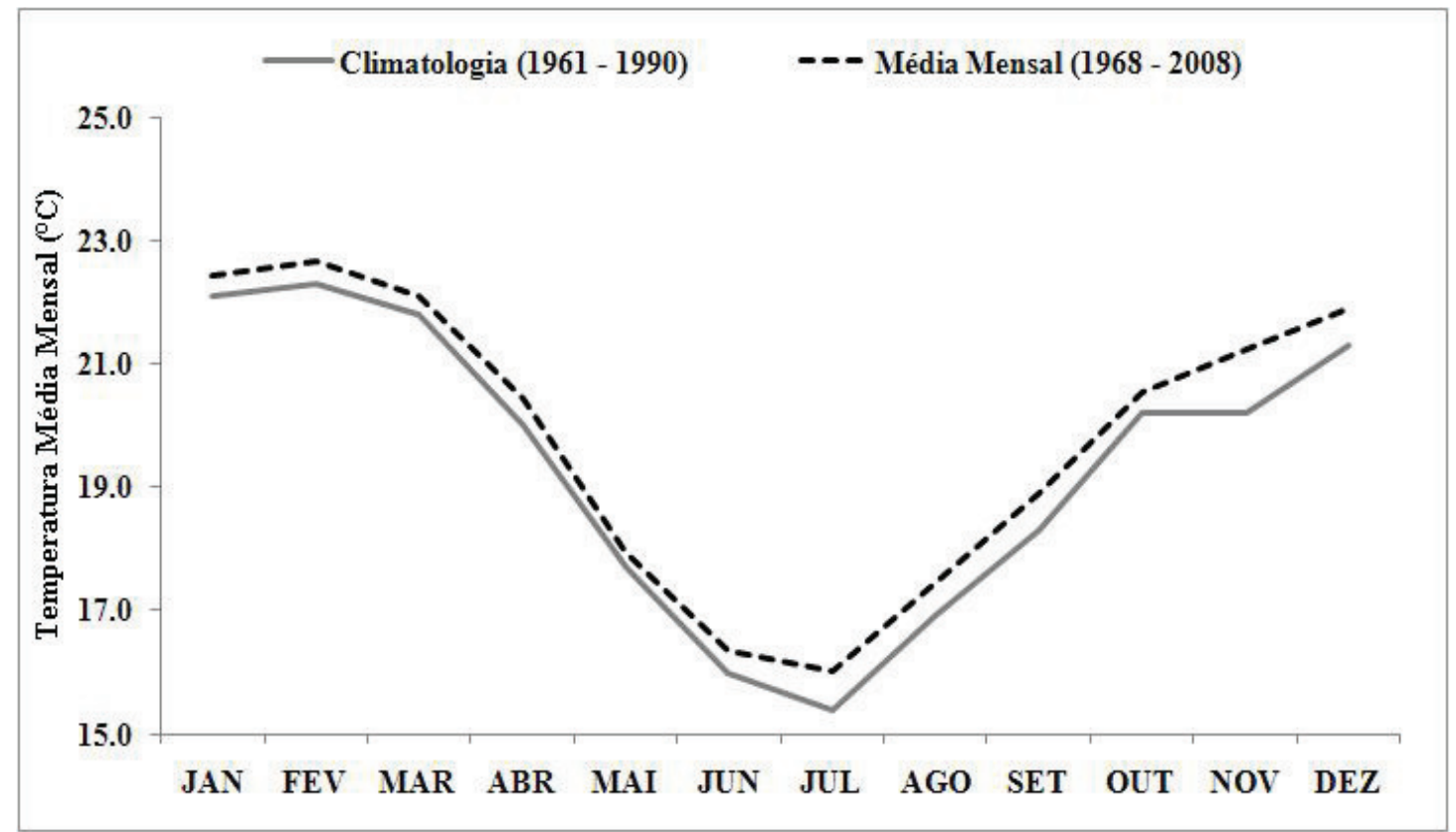

Figura 1: Distribuição da temperatura média mensal no município de Viçosa. Fonte: Departamento de Engenharia Agrícola/UFV. 
de dezembro e março, devido à maior incidência de radiação do hemisfério sul. Já as menores temperaturas médias são registradas entre os meses de maio a agosto, por motivos contrários aos das altas temperaturas, nesse período há menor incidência de radiação sobre a superfície do hemisfério sul, por estar no período de inverno. No entanto, observa-se que no período estudado (1968-2008) as médias da temperatura têm apresentado valores superiores aos da média histórica, indicando que as temperaturas apresentam acréscimos positivos nos últimos anos.

Como demonstrado na Figura 2, as temperaturas máximas médias registradas na estação entre 1968 e 2008, atingem seus valores mais elevados nos meses de fevereiro e março sendo $29,3{ }^{\circ} \mathrm{C}$ e 28,6 ${ }^{\circ} \mathrm{C}$ respectivamente, enquanto que a média histórica do INMET que compreende o período de 1961 à 1990 (BRASIL, 1992), apresentam pequenas oscilações em torno desses valores com temperaturas de $30^{\circ} \mathrm{C}$ e $28,4^{\circ} \mathrm{C}$ para os mesmos meses. De maneira geral observa-se que as temperaturas máximas têm demonstrado um ligeiro aumento de seus registros na maioria dos meses dos anos ao longo dos anos em relação à climatologia.

Como demonstrado na Figura 3, as temperaturas mínimas médias registradas na estação entre 1968 - 2008, atingem seus menores valores nos meses de junho e julho sendo respectivamente, $11,1{ }^{\circ} \mathrm{C}$ e

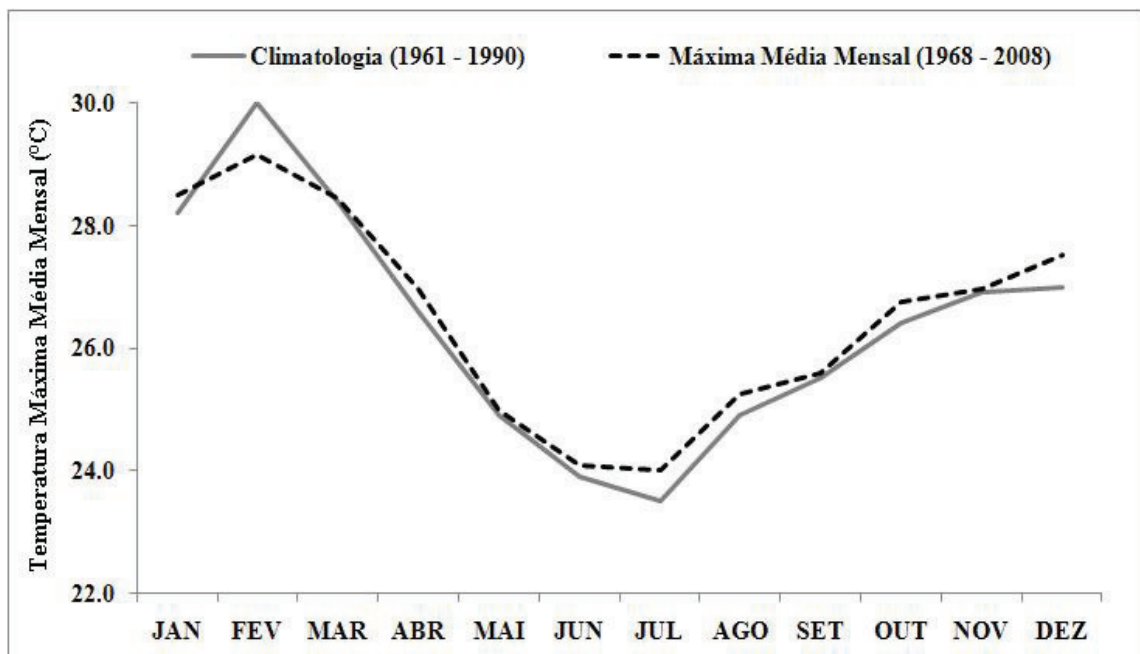

Figura 2: Distribuição da temperatura máxima média mensal no município de Viçosa. Fonte: Departamento de Engenharia Agrícola/UFV.

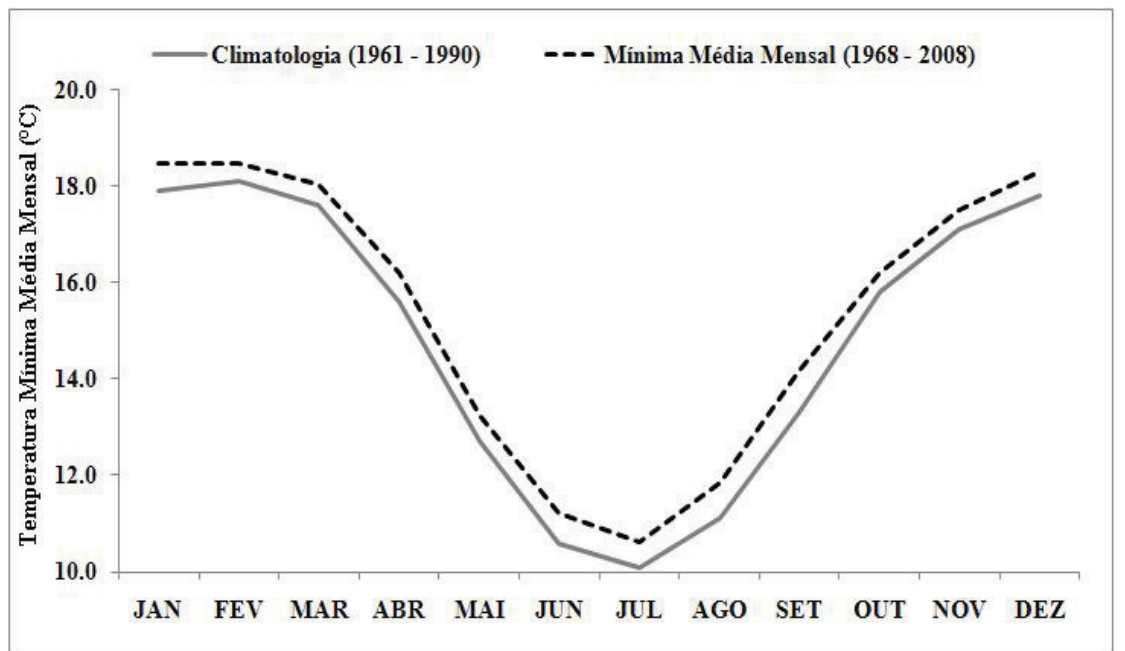

Figura 3: Distribuição da temperatura mínima média mensal no município de Viçosa. Fonte: Departamento de Engenharia Agrícola/UFV. 
Efeitos locais e de larga escala na dinâmica climática do município de Viçosa - Minas Gerais Jackson Martins Rodrigues, Rafael de Ávila Rodrigues, Flávio Barbosa Justino, Luiz Cláudio Costa, Marcelo Cid de Amorim

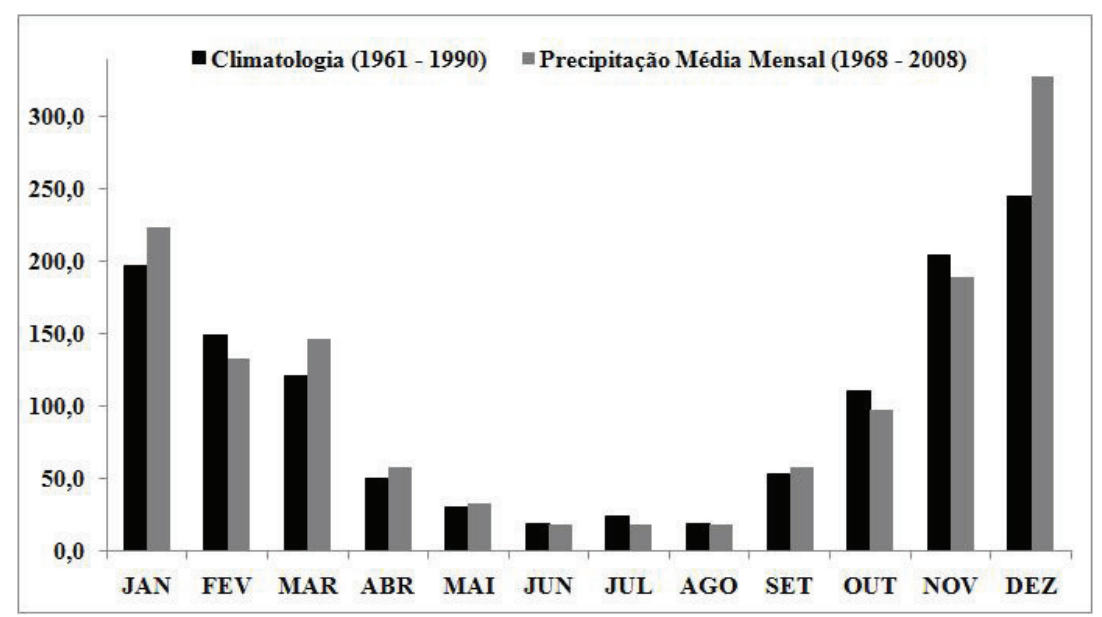

Figura 4: Distribuição da precipitação total mensal (mm) no município de Viçosa - Fonte: Departamento de Engenharia Agrícola/UFV.

$10,6{ }^{\circ} \mathrm{C}$, enquanto que a média histórica do INMET que compreende o período de 1961 à 1990 (BRASIL, 1992), apresentam pequenas oscilações em torno desses valores com temperaturas de $10,6^{\circ} \mathrm{C}$ e $10,1^{\circ} \mathrm{C}$ para os mesmos meses. Avaliando as temperaturas mínimas
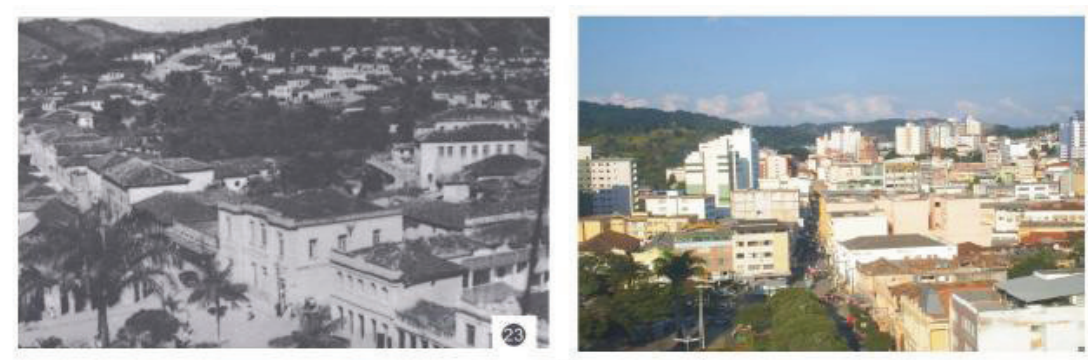

(A) no período estudado, observa-se que as mesmas têm apresentado um acintoso desvio positivo de seus valores em relação aos registros históricos.

Como demonstrado da Figura 4, a precipitação total mensal registrada na estação entre 1968 -

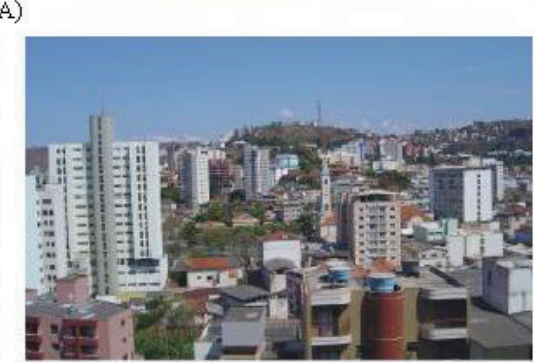

(B)
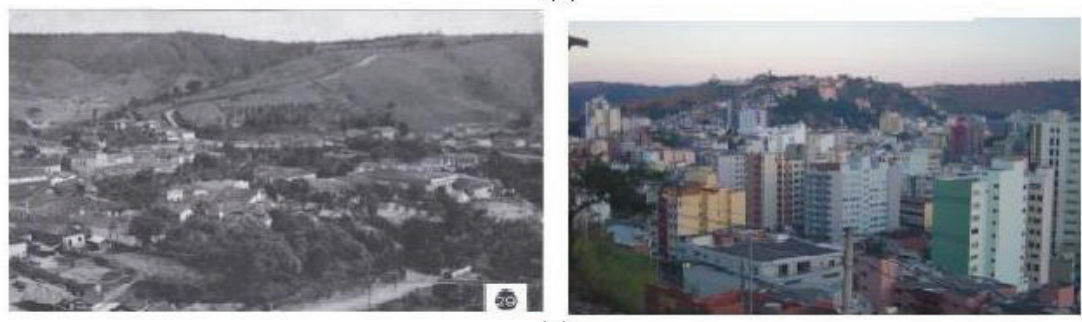

(C)

Figura 5: (A) Vista Parcial do Calçadão e Praça Silviano Brandão 1940 e 2006. (B) Vista Parcial de Viçosa 1945 e 2006. (C) Vista Parcial de Viçosa 1935 e 2006.

Fonte: AMORIM, 2006. 
2008 atingem seus valores mais elevados nos meses de mais quentes dezembro e janeiro, já os meses com menor precipitação compreendem os meses de temperatura mais baixa (junho e julho), enquanto que a climatologia do INMET que compreende o período de 1961 à 1990 (BRASIL, 1992), apresenta pequenas oscilações em torno desses valores e demonstrando o mesmo comportamento sazonal.

\section{Expansão urbana de Viçosa - MG e da UFV e sua relação com variação climática}

Vários aspectos demonstram o crescimento urbano de Viçosa além de sua notória expansão da área construída, como pode ser observado na Figura 5. Dentre os demais fatores relacionados ao seu crescimento, ao longo dos anos, destaca-se seu crescimento populacional, sua arrecadação de Imposto sobre Circulação de Mercadorias e Serviços - ICMS, seu consumo de água e o número de veículos registrados no município.

Como visto na Figura 6, o crescimento da população de Viçosa está fortemente ligado a migração de estudantes e profissionais oriundos de vários lugares do Brasil e do mundo. Os alunos são atraídos pela oportunidade de cursar ensino superior em uma instituição pública de qualidade e os profissionais das mais variadas áreas, são atraídas pelas oportunidades de emprego geradas direta e indiretamente pela UFV.

Ao migrarem para Viçosa, estes buscam se estabelecer nas proximidades das instituições de ensino e da rede de prestações de serviços da cidade, incrementando seu quadro populacional urbano bem como aquecendo sua economia. Cabe destacar ainda que, embora a rede de ensino viçosense tenha a UFV como principal fator de influência em seu crescimento, outras instituições de ensino superior particulares tem se instalado na cidade e desta forma incrementando seu ritmo de crescimento.

Desta forma o principal fator gerador de riquezas da cidade está baseado nas demandas geradas pelo setor de ensino, contando com várias pequenas empresas prestadoras de serviços e vasta rede de comércios. De fato, o município não tem expressiva atividade industrial - as ativas são de pequeno porte tende assim à medida que cresce a população, captar recursos em outras fontes, tais como: registros oriundos da construção civil, licenciamento e transferências de veículos, multas de trânsito, IPTU, juros, taxas etc. Assim, desde 1980, observa-se uma inversão na forma de arrecadação dos tributos. Trata-se de uma cidade essencialmente universitária, ou seja, o desenvolvimento

\section{Evolução da População}

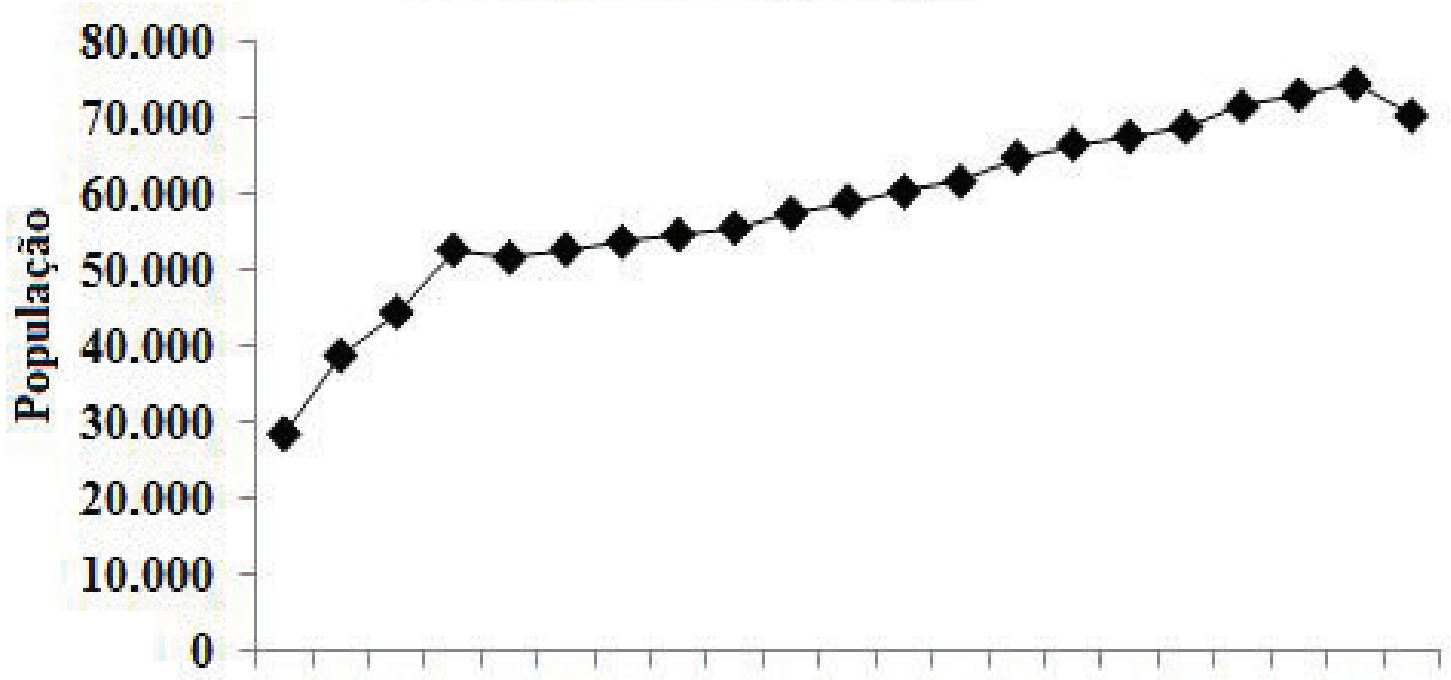

19741985199119931995199719992001200320052007

Figura 6: Evolução da População de Viçosa. Fonte: IBGE, 2000; IBGE, 2007. 
do município está diretamente relacionado à rede de prestação de serviços, estimulado pela demanda da da construção civil, licenciamento de veículos, multas de trânsito, outros impostos, juros, taxas etc.

Tabela 1: Viçosa em números, em 2004: Setor de atividade (Empresas Urbanas)

\begin{tabular}{l|r|r}
\hline Indústria & 122 & 1.166 \\
\hline Comércio & 927 & $50,3 \%$ \\
\hline Serviços & 101 & $40,0 \%$ \\
\hline Atividades não Empresariais & 2.316 & $4,4 \%$ \\
\hline Total & $100 \%$ \\
\hline
\end{tabular}

Fonte: Cruz et al. (2005)

rede de ensino, principalmente da UFV, escolas e outras universidades (Tabela 1).

Todavia, o crescimento da cidade de Viçosa pode ser observado também na Figura 7, onde se vê a marcha percentual anual do montante financeiro das suas fontes de arrecadação. Um município, basicamente, tem suas arrecadações provenientes de impostos, taxas e repasses dos governos que podem ser dividido
Outro importante fator relacionado ao crescimento populacional está ligado à demanda por bens materiais, principalmente, veículos que tem apresentado números crescentes de sua frota ao longo dos anos. O aumento da frota de veículos tem gerado vários transtornos a cidade, uma vez que seu sistema de vias não comporta mais tantos veículos circulando ao mesmo tempo, causando freqüentes transtornos

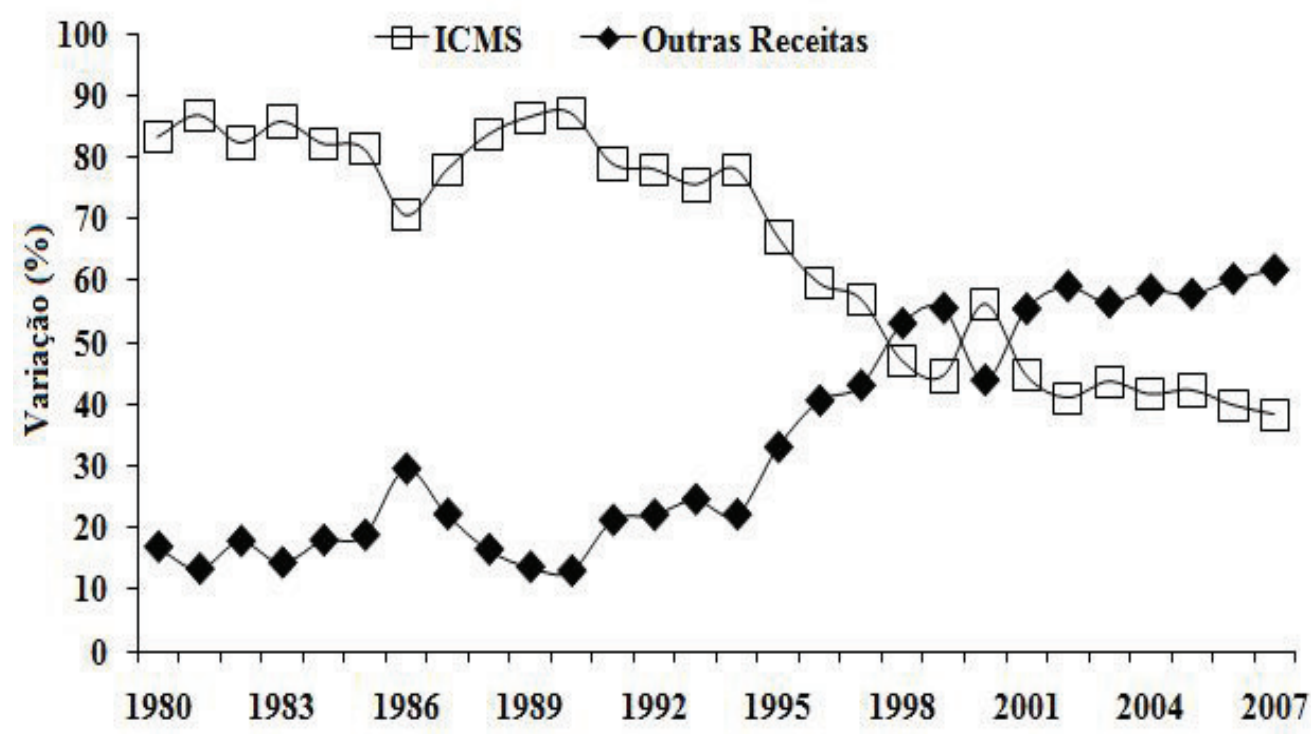

Figura 7: Arrecadações em Viçosa (MG). Fonte: Secretaria da Fazenda de Minas Gerais (SFMG).

em duas categorias: ICMS e outras fontes de receitas. Todavia, desde 1980, nota-se uma inversão na arrecadação municipal. Ou seja, o município por ter poucas indústrias - e as presentes são de pequeno porte - tende à medida que cresce reduzir, proporcionalmente, impostos na forma de ICMS. Em contrapartida, outras fontes de receitas totalmente em função da expansão urbana têm aumentado, tais como: registros oriundos como acidentes e congestionamentos em horários de pico, a evolução do número de veículos registrados em Viçosa pelo DETRAN-MG pode ser visto na Figura 8.

Outra importante informação sobre o crescimento de Viçosa diz respeito ao seu consumo de água, que tem alterado acintosamente seus padrões ao longo dos anos. O SAAE (2007), em seus levantamentos, aponta que mais de $98 \%$ da população recebe água tratada em 


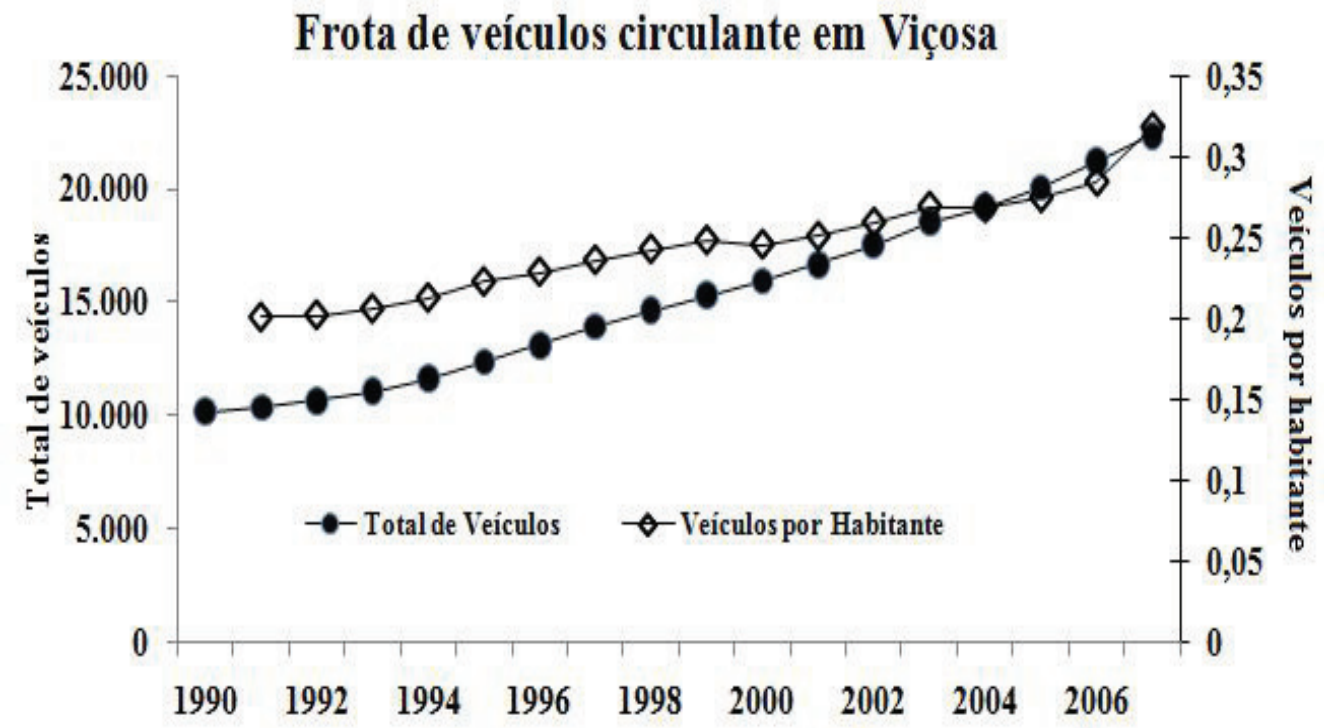

Figura 8: Frota de veículos circulantes de Viçosa - MG. Fonte: DETRAN-MG.

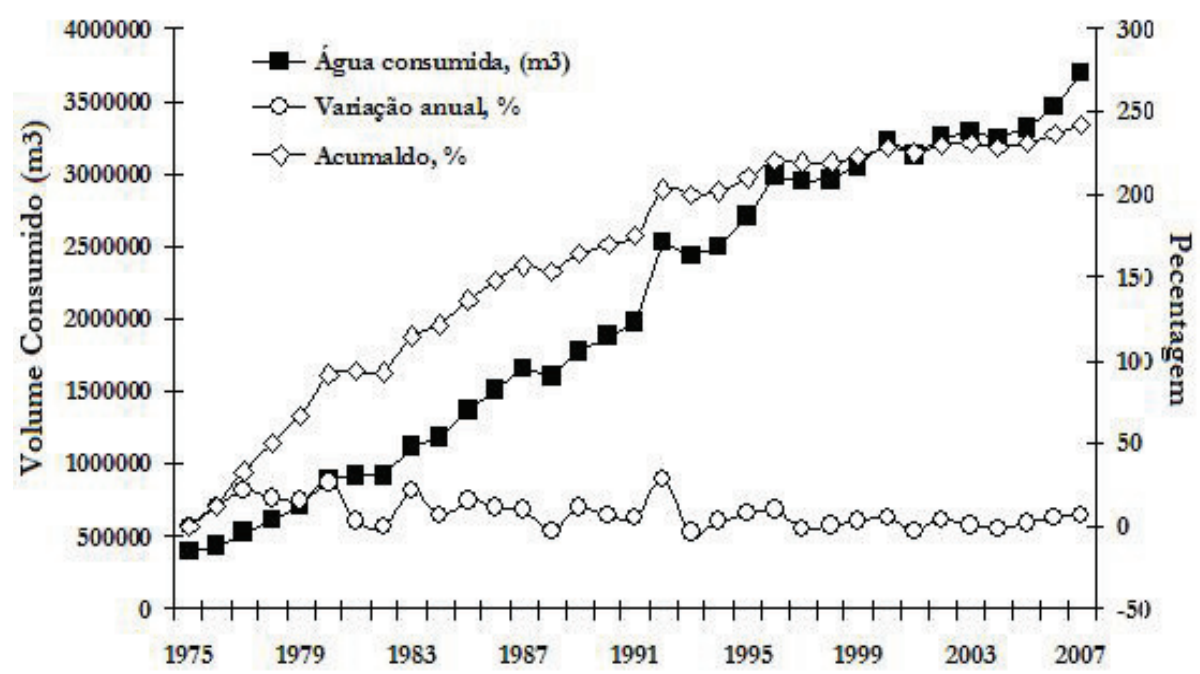

Figura 9: Consumo de água observada em Viçosa. Fonte: SAAE - Viçosa (MG).

suas residências. A Figura 9 mostra, entre 1975 e 2007, o volume anual de água consumida pela população de Viçosa e suas taxas de crescimento. O fornecimento, em 33 anos de monitoramento, mostra que o volume fornecido, em 2007, por exemplo, foi da ordem de $850 \%$ maior quando comparado com o fornecimento de 1975. Após 1992 a variação desta não ultrapassou os 10\%. Podendo atribuir este fenômeno as medidas operacionais estabelecidas pelo SAAE que vem tornado a distribuição mais eficiente, como por exemplo, a implantação de novas redes de fornecimento e a complementação do abastecimento por meio de outras adutoras. Por sua vez, anos com taxas negativas sugerem crises e racionamentos no fornecimento - comuns em anos com chuvas abaixo da média.

\section{Análise Climática}

Normalizações das variáveis climatológicas

A Figura 10 representa as séries de registros meteorológicos coletados na estação do INMET 


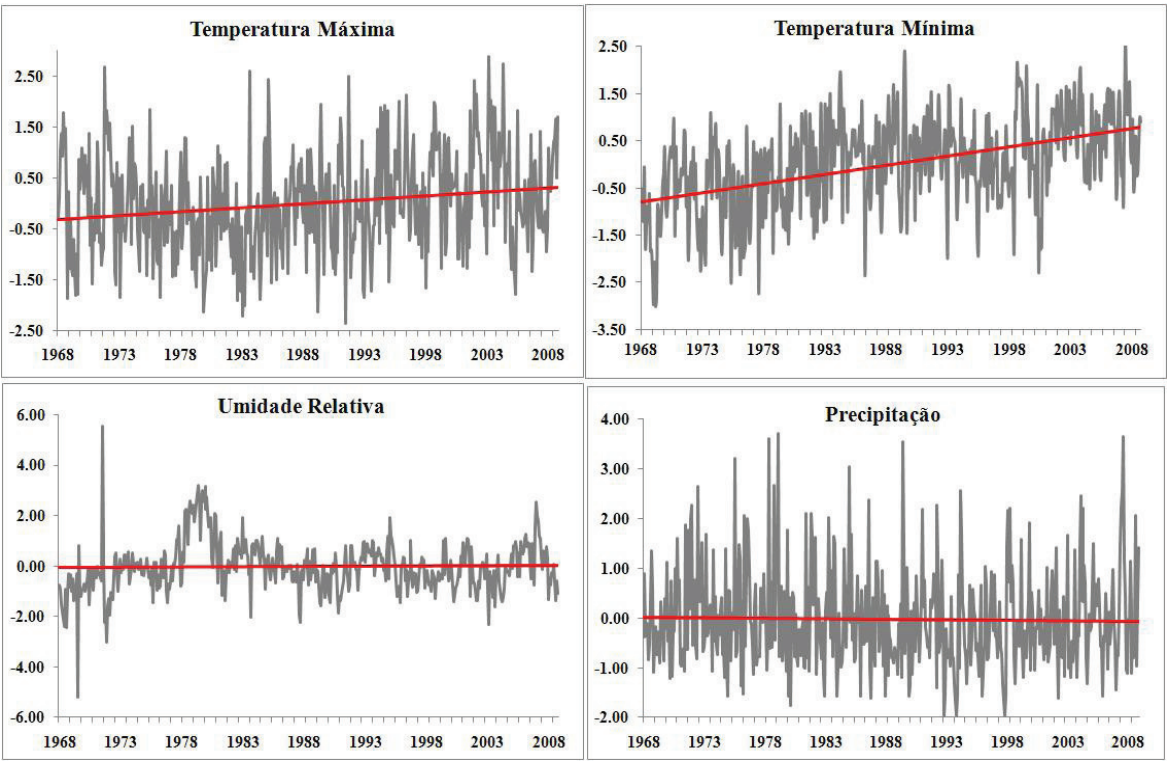

Figura 10: Normalização das variáveis meteorológicas (temperaturas máximas e mínimas, umidade relativa e precipitação)

instalada na UFV. Tais dados demonstram o comportamento mensal real das variáveis meteorológicas no período de 1968 a 2008 para as temperaturas máximas e mínimas, precipitação e umidade relativa.

A padronização dos registros retirou suas tendências e retrata uma tendência, estatisticamente, mais realística. Pelos gráficos observa-se que a temperatura máxima tem alterado seu comportamento, demonstrando um pequeno desvio positivo com o passar dos anos. Já a temperatura mínima foi que demonstrou maiores alterações em seu comportamento com expressivo desvio positivo indicando que os períodos em que não há incidência do sol estão ficando mais quentes.
A padronização dos dados de umidade relativa e precipitação não demonstraram tendências, ou seja, apresentaram distribuições aleatórias por não estarem sofrendo influências de qualquer fator.

\section{Teste Mann-Kendall}

Os resultados mensais observados na temperatura mínima foram diferentes em relação à temperatura máxima, na maioria dos casos, as séries de temperatura mínima apresentam tendência positivas. Essa diferença de aumento entre a temperatura máxima e mínima é refletida nos valores

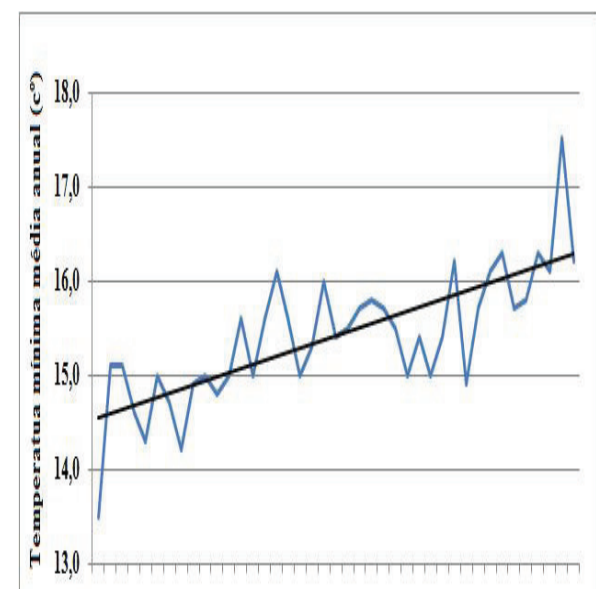

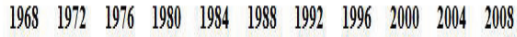

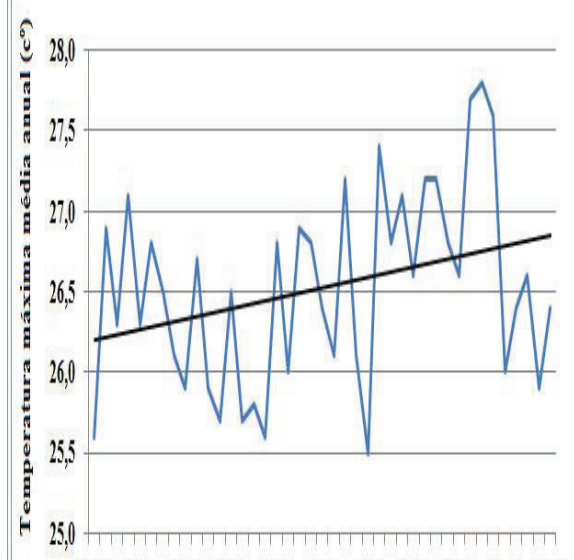

$19681972 \quad 197619801984198819921996200020042009$

Figura 11: Variação anual das temperaturas máximas médias de 1968 a 2008 em Viçosa, MG. 
da amplitude térmica (diferença entre a temperatura máxima e mínima) ao longo dos anos, isto significa que caso essa tendência se mantenha, espera-se uma diminuição na amplitude térmica.

Os testes de Mann-Kendall para as médias mensais de temperatura mínima e máxima são apresentados na Tabela 2 e Figuras 11 e 12, respectivamente. Verificou-se uma tendência positiva na temperatura mínima em quase todos os meses, com exceção dos meses de junho, agosto e novembro que não apresentaram tendência significativa. Já as análises da temperatura máxima não apresentaram tendência significativa, com exceção dos meses de abril, setembro e outubro que apresentaram tendência positiva.

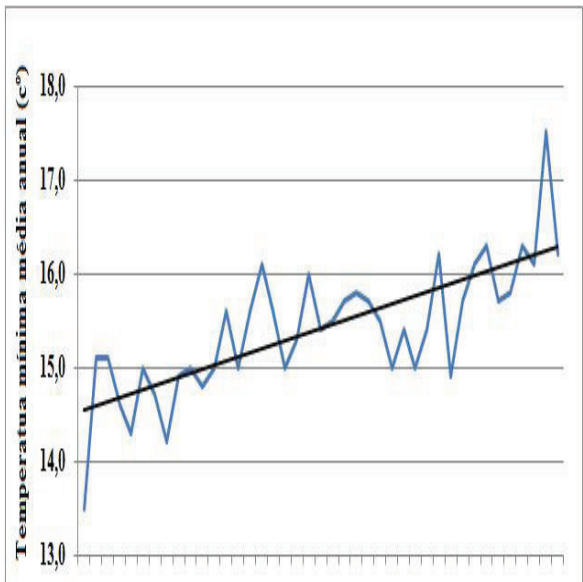

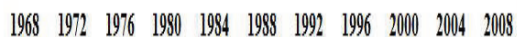

Os desvios positivos apresentados pelas temperaturas, podem ser explicados pela razão de mistura, que expressa em gramas de vapor por quilograma de ar seco da atmosfera do município. A figura 13 demonstra os valores normalizados da razão de mistura.

O aumento da precipitação nos meses de dezembro, janeiro, março e abril como apresentados na Figura 4, sugerem o aumento da quantidade de vapor d'água presente na atmosfera, influenciando positivamente as temperaturas, principalmente as mínimas.

A Figura 14 mostra alta correlação entre a temperatura mínima e a pressão de vapor da ordem

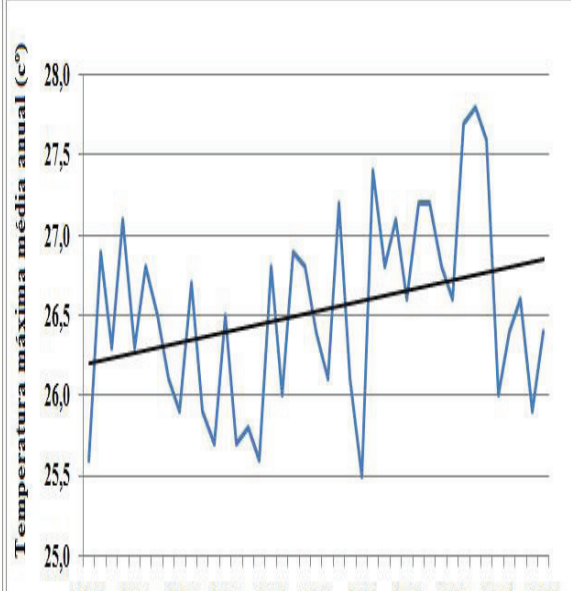

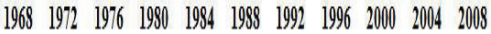

Figura 12: Variação anual das temperaturas mínimas médias de 1968 a 2008 em Viçosa, MG.

Tabela 2: Resultados das análises de tendência para a temperatura média mínima de cada mês.

\begin{tabular}{c|c|c}
\hline Temperatura & Teste de Mann_Kendall \\
Mínima & (Z Calculado) & Tendência $\alpha=0,05$ \\
\hline Janeiro & 3.92 & $\mathrm{~S}+$ \\
Fevereiro & 3.65 & $\mathrm{~S}+$ \\
Março & 2.92 & $\mathrm{~S}+$ \\
Abril & 3.34 & $\mathrm{~S}+$ \\
Maio & 2.18 & $\mathrm{~S}+$ \\
Junho & 1.74 & $\mathrm{~S}+$ \\
Julho & 2.11 & $\mathrm{NS}$ \\
Agosto & 1.40 & $\mathrm{~S}+$ \\
Setembro & 2.13 & $\mathrm{~S}+$ \\
Outubro & 2.00 & $\mathrm{NS}$ \\
Novembro & 1.86 & $\mathrm{~S}+$ \\
Dezembro & 3.85 & $\mathrm{~N}$ \\
\hline
\end{tabular}

NS = Tendência não significativa; S+ = Tendência significativa positiva; S- = Tendência significativa negativa 


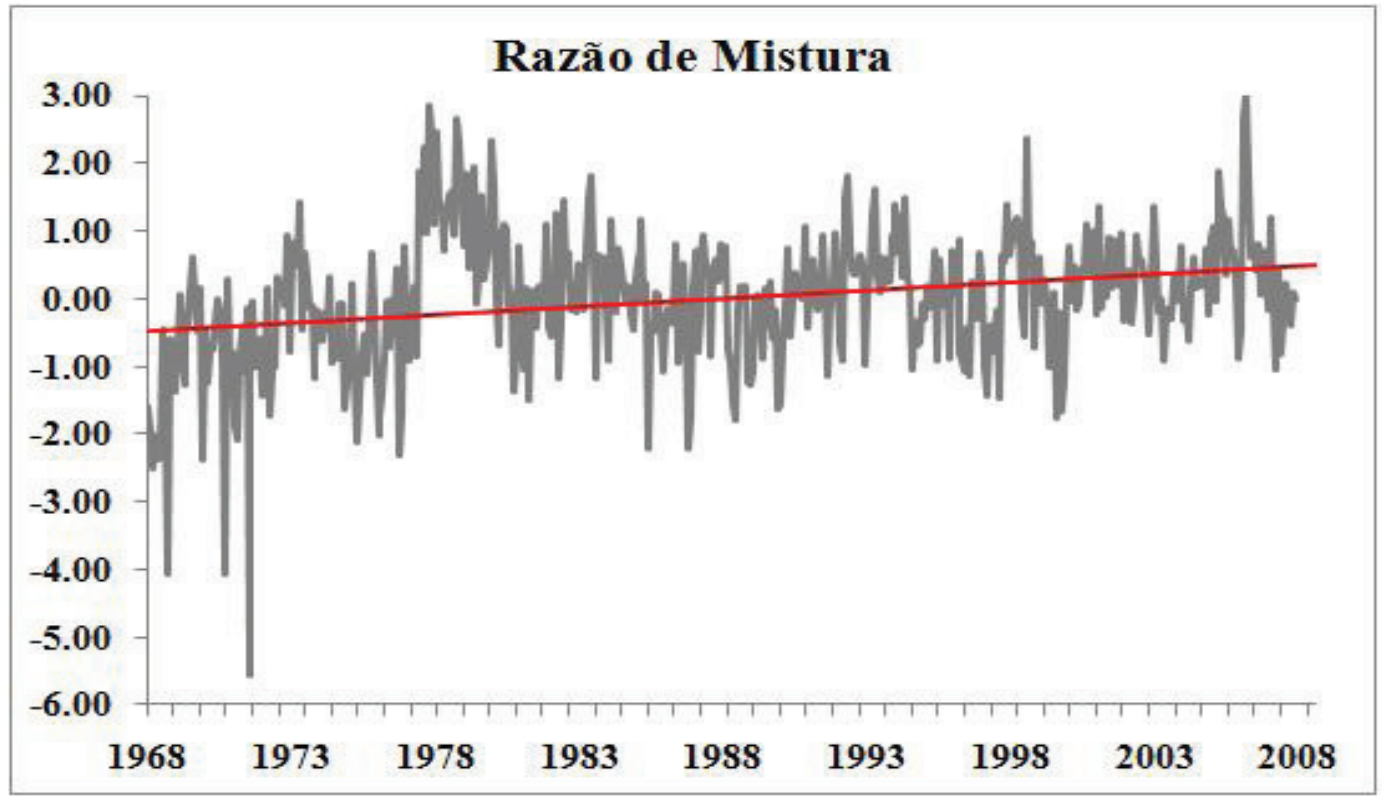

Figura 13: Variação anual da pressão de vapor d'água e pressão de saturação.
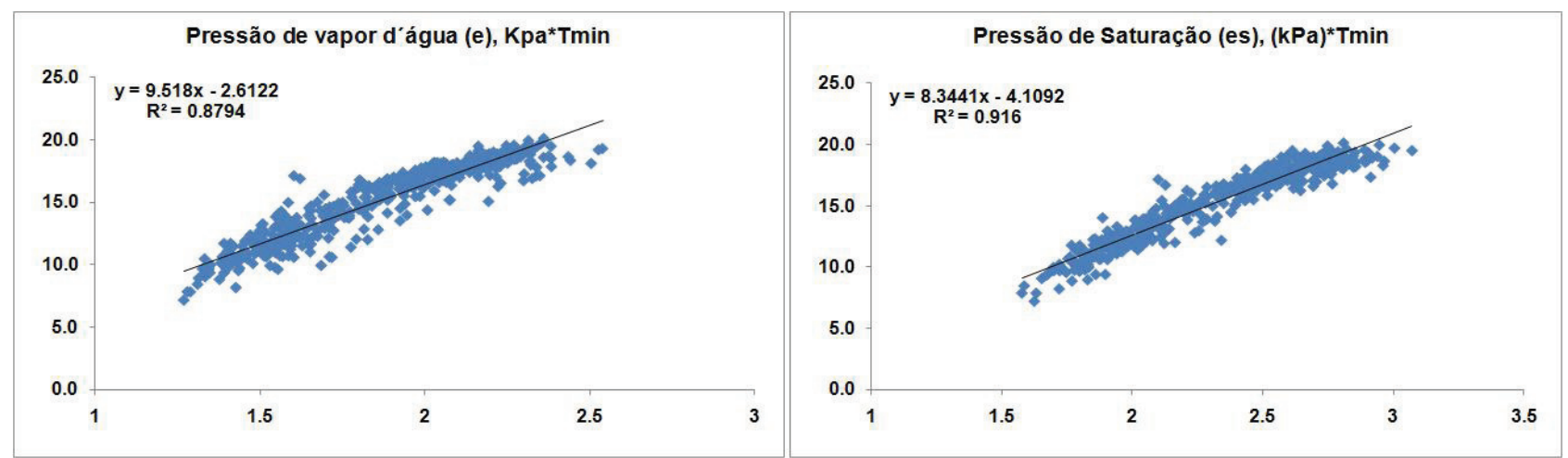

Figura 14: Análise de Correlação entre a temperatura mínima e pressão de vapor d'água e temperatura mínima e pressão de saturação

$$
\text { de Viçosa - MG. }
$$

$87 \%$ e entre a temperatura mínima e pressão de saturação da ordem de 91\%. Uma das características do vapor d'água é sua capacidade de absorção de radiação que acarreta o aumento da temperatura, desta maneira o aumento na quantidade de vapor na atmosfera de Viçosa explica o desvio positivo da temperatura.

Análise dos dados: Reanálise NCEP versus INMET

A figura 15 demonstra o comportamento das séries históricas das temperaturas médias da Região Sudeste, Minas Gerais e de Viçosa - MG. Comparando os dados de temperatura de Viçosa com a Região Sudeste bem como com Minas Gerais, observa-se que não há significativas alterações nos comportamentos das séries, ou seja, o comportamento das temperaturas médias em macro escala (Minas Gerais e Região Sudeste) não destoa das observadas em micro escala (Viçosa - MG). Desta forma pode-se concluir que não há alterações nas séries de temperatura média de Viçosa que não seja observada em sistemas maiores como a circulação atmosférica.Assim, o $\mathrm{n}$ amostral de 492 e níveis de significância iguais a 10\%, 5\% e $1 \%$ os valores críticos da tabela t de student são 1,64 ; 1,96 e 2,58, respectivamente, rejeitando-se a hipótese que a correlação entre as variáveis é igual a zero, pois o valor de t observado é maior que o valor crítico. Assim, conclui-se que a correlação entre as variáveis é estatisticamente significativa, ou seja, rejeita a hi- 


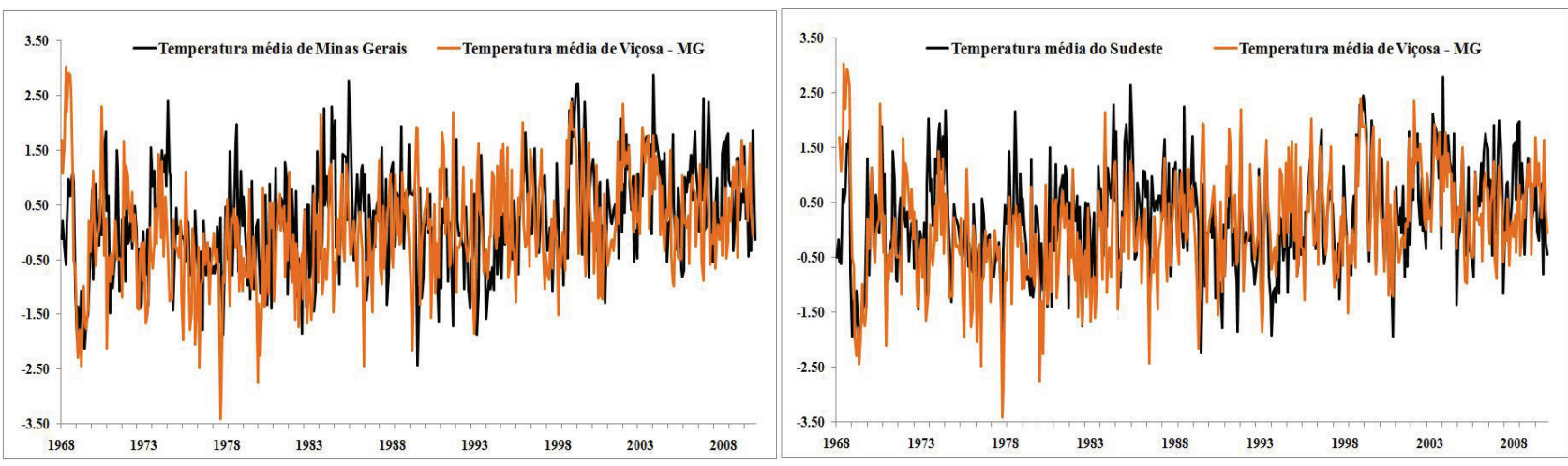

Figuras 15A e 15B: Série histórica da temperatura média da Região Sudeste, Minas Gerais e Viçosa - MG (1968 - 2008): INMET. Fonte: NCEP-Reanalysis (http://www.cdc.noaa.gov/cgibin/data/timeseries/timeseries1.pl).
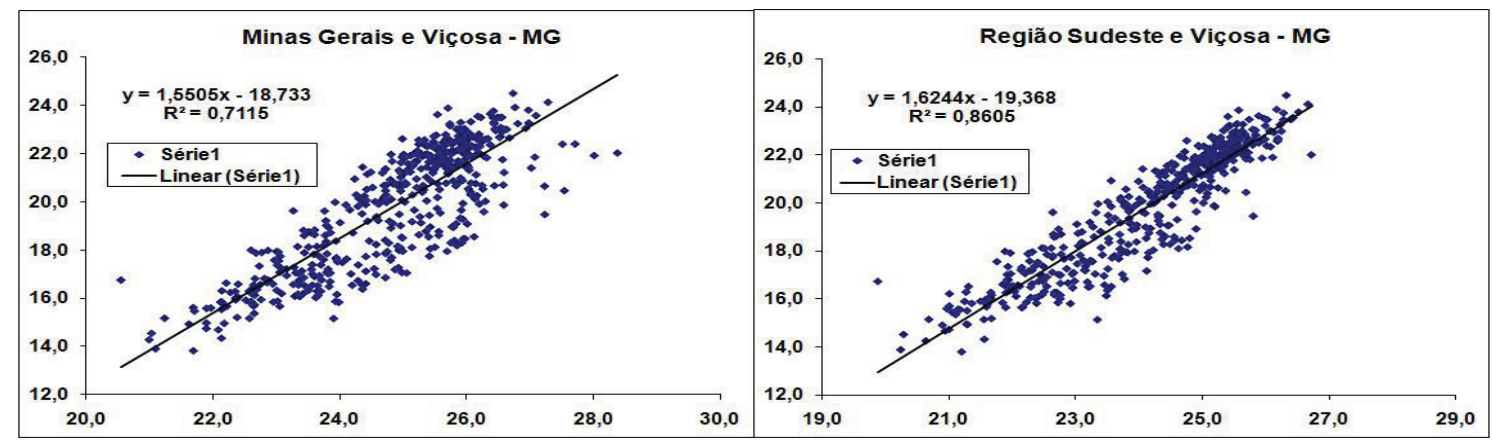

Figura 16A e 16B: Análise de Correlação entre as temperaturas médias da Região Sudeste e Viçosa - MG e Minas Gerais e Viçosa MG.

Tabela 3: Resumo Estatístico da análise de Correlação.

\begin{tabular}{|c|c|c|c|}
\hline $\boldsymbol{\alpha}$ & $\mathbf{1 0 \%}$ & $\mathbf{5 \%}$ & $\mathbf{1 \%}$ \\
\hline $\mathbf{t}^{\mathbf{c}}$ & 1,64 & 1,96 & 2,58 \\
\hline $\mathbf{n}$ & \multicolumn{2}{|c|}{492} \\
\hline $\mathbf{G L}$ & Minas Gerais x Viçosa & Região Sudeste $\mathbf{x}$ Viçosa \\
\hline \multicolumn{3}{|c|}{0,71} & 0,86 \\
\hline $\mathbf{R}^{2}$ & 29,18 & 50,88 \\
\hline $\mathbf{t}$ calc. &
\end{tabular}

pótese $\mathrm{h}_{0}$ pois os valores estão dentro do intervalo de confiança, conforme Tabela 3.

Em ambos os casos sendo $n=492$ meses $(1968$ a 2008), foram testados 3 níveis de significância :10\%, $5 \%$, e $1 \%$ conforme segue (Tabela 3 ).

\section{CONCLUSÕES}

O crescimento urbano do município de Viçosa é impactante e notório. Todo esse crescimento está diretamente relacionado no aumento de habitantes que vem aquecendo a economia como observado nos dados de arrecadação de ICMS, número de veículos e até no fornecimento de água a população. Associado ao crescimento da cidade também se deve considerar a expansão da UFV.

Essa expansão vem acarretando uma maior demanda por recursos como água que segundo dados do SAAE sua tendência crescente de consumo poderá acarretar escassez em sua oferta em alguns anos. 
Embora Viçosa tenha apresentado nos últimos anos tamanho crescimento urbano, não se pode afirmar que possa estar influenciando seu clima uma vez que o comportamento de suas variáveis meteorológicas não se diferenciam das variáveis relacionadas à uma escala maior sendo ela a Região Sudeste ou o Estado de Minas Gerais.

Pela normalização foi possível observar os reais comportamentos das séries históricas climáticas coletadas na estação de Viçosa, bem como através do teste Mann-Kendall foi possível identificar tendências de aumento na temperatura mínima e que este aumento está relacionado à maior concentração de água na atmosfera.

As técnicas estatísticas utilizadas no presente artigo permitem análises mais abrangentes e completas sobre os comportamentos das séries climáticas fornecendo subsídios para conclusões mais contundentes sobre as anomalias apresentadas em alguns parâmetros climáticos.

Pela análise comparativa das temperaturas médias da Região Sudeste e de Minas Gerais com a de Viçosa é observado que os seus comportamentos estão seguindo padrões muito semelhantes. Pela regressão linear observa-se alta correlação entre as variáveis de micro e macro escalas se mostrando estatisticamente significativas a correlação entre as variáveis.

\section{AGRADECIMENTOS}

Ao CNPq pela concessão da Bolsa de Iniciação Científica para o desenvolvimento do presente trabalho, que posteriormente foi concretizado na Monografia do Curso Geografia da UFV.

\section{REFERÊNCIAS}

ALCÂNTARA, B. G.; A percepção climática no município de Viçosa Minas Gerais. 2008. 106 p. Monografia (Graduação em Geografia) - Universidade Federal de Viçosa, Viçosa: UFV, 2008. Disponível em: $<$ http://www.geo.ufv.br/monografias.php $>$ Acesso em: 12 abr. 2009.
AMORIM, I. C. Patrimônio Histórico: História, cultura e valores. Viçosa (MG). 2006. 127 p. Monografia (Graduação em Arquitetura e Urbanismo) - Departamento de Arquitetura e Urbanismo, Universidade Federal de Viçosa: UFV. 2006.

AMORIM, M. C. de C. T. Características do clima urbano de Presidente Prudente. In: SANT'ANNA NETO, J. L (Org.), Os Climas das Cidades Brasileiras. Presidente Prudente: FCT/UNESP, 2002.p. 165-195.

ARAÚJO, R. R.; SANT'ANNANETO, J. L. O processo de urbanização na produção do clima urbano de São Luís - MA. In: SANT'ANNA NETO, J. L (Org.), Os Climas das Cidades Brasileiras. Presidente Prudente: FCT/UNESP, 2002. p. $21-41$.

BRASIL. Ministério da Agricultura e Reforma Agrária - Secretaria Nacional de Irrigação - Departamento Nacional de meteorologia. Normais climatológicas (1961 - 1990). Brasília, DF, 1992.

CRUZ, T.A.; ALVARENGA, S.C.; SILVA, A.R.; CARMO, M.I. Perfil empresarial de Viçosa. ViçosaMG: Census, 2005.

DUTRA C. A.; COUTINHO, E. A.; FIALHO, E. S. As alterações climáticas e o crescimento desordenado das cidades: um estudo de caso da cidade de Viçosa-MG. In: VII SIMPÓSIO BRASILEIRO DE CLIMATOLOGIA GEOGRÁFICA, 2006, Rondonópolis. Anais... Rondonópolis: Laboratório de Climatologia, 2006.

INSTITUTO BRASILEIRO DE GEOGRAFIA E ESTATÍSTICA - IBGE. Censo Demográfico do ano 2000. Rio de Janeiro: IBGE, Rio de Janeiro. 2000.

. Aspectos da Contagem da População 2007. Rio de Janeiro: IBGE, outubro de 2007. 311p. Disponível em: http://www.ibge.gov.br/home/estatistica/ populacao/contagem2007/contagem.pdf Acesso em: 28 abr. 2009.

MINGOTI, S. A. Análise de dados através de métodos de estatística multivariada: uma abordagem aplicada. Belo Horizonte: UFMG, 2007. 
MONTEIRO, C. A. de F. O clima e a organização do espaço no estado de São Paulo. Série Teses e Monografias, n. 28, São Paulo: USP/Igeog, 1976.

OKE, T. R. Boundary Layer Climates. 2 ed. London: Ethuen \& CO, 1978.

QUEREDA SALA, J.; GILOLCINA A.; PEREZ CUEVAS A.;OLCINA CANTOS J.; RICO AMOROS A.; MONTÓN CHIVA E. Climatic warming in the Spain Mediterranean: natural trend or urban efect. Netherlands, v. 46, n.4, p. $473-483$, set. 2000.

SAAE - Serviço Autônomo de Água e Esgoto de Viçosa, MG. Relatório anual 2007. Viçosa-MG, 2007.

SANTOS, R. F. dos. Vulnerabilidade ambiental organizadora. Brasília: MMA, 2007.

SAYDELLES, A. P. Estudo do campo térmico e das ilhas de calor urbano em Santa Maria-RS. Santa Maria:UFSM, 2005. 237 p. Dissertação (Mestrado em Geografia) - Programa de Pós-Graduação em Geografia e Geociências. Universidade Federal de Santa Maria Brasil, Santa Maria, 2005

SILVEIRA, V. P.; GAN, M. A. Estudo de tendência das temperaturas mínimas na Região sul do Brasil. In: CONGRESSO BRASILEIRO DE METEOROLOGIA, 14. Florianópolis. Anais... Florianópolis, 2006.

SPIRN, A. W. O Jardim de Granito: A natureza do Desenho da Cidade. São Paulo: Editora da USP, 1995.

YU, P.; YANG, T.; WU, C. Impact of climate change on water resources in southern Taiwan. Journal of Hydrology, Amsterdam, v.260, p.161 - 175, 2002. 